\title{
Just a guy in pajamas? Framing the blogs in mainstream US newspaper coverage (I 999-2005)
}

(C) The Author(s) 2010 Reprints and permission: http://www. sagepub.co.uk/journalsPermission.nav DOI: |0.1 |77/|46|444809342524 http://nms.sagepub.com

@SAGE

\author{
Julie Jones \\ University of Oklahoma, USA
}

\section{Itai Himelboim}

University of Georgia, USA

\begin{abstract}
When new technologies are introduced to the public, their widespread adoption is dependent, in part, on news coverage (Rogers, 1995). Yet, as weblogs began to play major role in the public spheres of politics and journalism, journalists faced a paradox: how to cover a social phenomenon that was too large to ignore and posed a significant threat to their profession. This article examines how blogs were framed by US newspapers as the public became more aware of the blogging world.A content analysis of blog-related stories in major US newspapers from 1999 to 2005 was conducted. Findings suggest that newspaper coverage framed blogs as more beneficial to individuals and small cohorts than to larger social entities such as politics, business and journalism. Moreover, only in the realm of journalism were blogs framed as more of a threat than a benefit, and rarely were blogs considered an actual form of journalism.
\end{abstract}

\section{Key words}

blogs, framing, mainstream media

\section{Introduction}

In the past decade, a new type of mass communication medium, suggested by some as a form of grassroots journalism, has risen: the blog (Gillmor, 2004). Recent trends indicate a shift toward this new medium of news and information. Pew Internet and American Life Project data indicated that typical blog readership (persons likely to

\footnotetext{
Corresponding author:

Julie Jones, Gaylord College of Journalism and Mass Communication, University of Oklahoma, 395 W. Lindsey, Norman, OK 73019, USA.

Email: juliejones@ou.edu
} 
read a blog in a given day) increased by 33 percent in 2008, while those who report having posted their opinions on a news site or group rose to 22 percent (Smith, 2008). In the news-gathering realm, a record number of bloggers were credentialed for the 2008 US presidential conventions (08DNC, 2008; Casey, 2008). Bloggers' attendance at large-scale political events, along with blogs' increasing popularity with news consumers, challenges the notion that a blogger is, in a former CBS news executive, Jonathan Klein's, description, merely 'a guy sitting in his living room - in his pajamas - writing' (2004).

In an age of media concentration, convergence and reconfiguration, this individual-based information gathering, collaboration, distribution and consumption raises many questions. Could blogs be an alternative, competing, or, at the very least, complementing sources of information already supplied by professional journalists? This paradigm presents a paradox: just as journalism is the first draft of history, newspaper articles provide many citizens with a framework for understanding an emerging phenomenon as it progresses into mainstream adoption (Rogers, 1995). In Schudson's (1995) wording, news is a cultural product that generates public knowledge (p. 1). Traditional news organizations which are culturally rooted in normative principles of objectivity, gatekeeping and the watchdog function, may perceive bloggers fulfilling a press function as a dangerous notion - a danger for the individual journalist, the industry at large and a society ill-equipped to decipher 'the truth' among a cacophony of voices.

To confound the issue further, bloggers often value their oppositional position outside the mainstream media. Yet even when they are most influential (as in their collective challenge of CBS's '60 Minutes' coverage of President Bush's service records), bloggers' power does not lie solely within the blogosphere. Often, only when the mainstream press adopts an issue as worthy of news coverage can the bloggers' buzz be translated into a change at the societal level.

This article links old and new media from a historical standpoint; it examines how US newspapers framed the blogosphere during its formative years. A content analysis of blog-related stories in major US newspapers from 1999 to 2005 was conducted. Three main topics were examined:

1. The value of blogs - were blogs framed as a benefit or a threat, and to whom?

2. The narrative of the story - were blogs framed as a new or common phenomenon, and how does this frame change over time?

3. Bloggers as journalists - do articles label bloggers as journalists or associate blogging with journalism?

The potential of the internet to become a meaningful and viable source of information, opinions and ideas depends on social attitudes as much as it does on the availability of technology. However, social attitudes depend, in part, on the stories written by traditional gatekeepers, professional journalists. How did these journalists cover an information revolution with the potential not only to tear down the gates, but to threaten those who keep the keys? 


\section{The intersection of the bloggers, the press and the public}

Any attempt to understand how traditional media portray blogs to the public must begin with an exploration of the interests of the parties in this trinity. We begin with the public.

The public has an interest in access to opinions and credible information across a wide range of topics (Picard, 1994). Blogs can be seen as a symbolic bridge between traditional social institutions and the public (Quandt, 2005). On the one hand, blogs provide anyone access to publication for personal or more altruistic motives. Bloggers are part of the public itself, and act as a collective, collaborative force that aggregates knowledge, opinions and advice. In this manner, blogs employ the 'wisdom of the crowd' (Surowiecki, 2004) and invite anyone to participate via posts and comments. On the other hand, some bloggers see themselves as fulfilling journalistic roles or providing unique perspectives that journalists, rooted in collective and professionalized culture, overlook (boyd, 2004; Gillmor, 2004).

Furthermore, from 1999 to 2005 (this study's timeframe) weblogs evolved from a novelty to a more mainstream phenomenon. This presented journalists with a professional dilemma: how to introduce the blogosphere to the public, cover its emergence as a medium of discourse and discovery, and, at the same time, confront the challenges that blogs present to journalism's professional boundaries. The relationship between blogs and journalism is discussed next, from both perspectives.

\section{Blogs, bloggers and their intersection with the press}

Blogs are 'frequently modified web pages containing dated entries listed in reverse chronological sequence' (Herring et al., 2005: 142). Most bloggers use their online tools to post content personal to their lives and families. Herring and her colleagues (2004, 2006) have labeled this type of blog as a personal journal. Though fewer in numbers, filter-type blogs, where bloggers post content external to their lives, garner the majority of press and scholarly attention. In this corner of the blogosphere where political and news blogs reside, many blogging enthusiasts perceive the interactive nature of blogs as nothing less than the long-awaited egalitarian promise of the internet and the world wide web. Many of these writers trace the function of blogs back to the earliest online endeavors, including the first online community, The Well (Kline and Burstein, 2005); the first web pages created through Tim Berners-Lee's Hypertext Markup Language (HTML) innovation (Gillmor, 2004; Winer, 2002); and the earliest online bulletin boards (Trippi, 2004). Burstein (2005) reaches further back into history to argue that Thomas Paine, the political thinker so crucial to the American revolution, was the first blogger.

The currently used weblog format appeared in 1997 (Winer, 2002), but did not gain wide popularity, as proficiency in HTML language was necessary to create a blog. In 1999 the San Francisco-based Pyra Lab, founded by Meg Hourihan and Evan Williams, introduced Blogger. It was user-friendly software that lowered the skill bar necessary to create a blog and allowed the HTML-illiterate to publish content online. Following its introduction, anyone with a broadband connection, the desire and the time could launch their own public site (Blood, 2000).

Blogs' current features can be traced to the period of weblog development shortly before and after Blogger's debut. Pre-Blogger sites provided services similar to an online 
editor's role by pointing out useful links to visitors. These links connected to interesting websites and reports, and were of great help to those lost in an ever-expanding and confusing Web universe (Blood, 2000). The progeny of this feature is the frequently used blogroll, a list of salient blogs handpicked by the blogger.

Once the Blogger web application was released, bloggers' posts became more personalized and informal. Rebecca Blood (2000) traces this change back to Blogger's developers, Hourihan and Williams, whose own blogs were presented in a brisk, light and personal writing style that many began to emulate.

After the events of 11 September 2001, weblogs became increasingly political and journalistic in nature. In the initial days after the attack on the USA, many used blogs as means of emotional expression and connection (Jesdanun, 2001; Schorow, 2001). Soon thereafter, the war blog format emerged (Gallagher, 2002). Prior to 11 September, bloggers functioned as watchdogs, most notably in their exposure of an online scam centered on a fictitious teenager's struggle and death from leukemia (Hafner, 2001). This watchdog role continued as bloggers found collective force in challenging CBS's reports on Bush's service (Preiss, 2004), shedding light on Trent Lott's praise of Strom Thurmon's 1948 segregationist presidential campaign (Canfield, 2002), and publishing lurid emails from Congressman Mark Foley to his male pages, beating mainstream media to the punch (Thomas, 2006). In addition, bloggers began to publish first-hand, eyewitness accounts of news events (notably, but not limited to, spot news such as the London transit bombings, the tsunami disaster and the Hurricane Katrina aftermath). With their 'random acts of journalism' (Lasica, 2003), bloggers outperformed the mainstream press by publishing as-it-happens, highly localized information continuously and reliably in dynamic situations (Norris, 2006).

Bloggers are keen to recognize that a shift in power is occurring in journalism. The blogosphere is not a passive audience comfortable in a mass media, mass audience world. Gillmor (2004) and Rosen (2004a) use terms such as 'grassroots journalism' or 'news turning from lecture to conversation'. They argue that journalists should adopt a key attribute of the online world by embracing an 'open source' philosophy (Gillmor, 2004: 16-18; Rosen, 2004b) or, in Gillmor's words, accept that 'readers know more than I do' (Gillmor, 2003: vi). Blood (2003), a blog pioneer, argues a counter-point when she contends that blogs miss an essential element of information gathering that only journalists can provide: original, in-depth coverage. Still, with the concentration of media organizations into the control of a few mega-conglomerates (Bagdikian, 2004), blogs can be seen as providing important, alternative news and viewpoints. From journalism's perspective, however, blogs may be seen as a potential threat to the press's unique role as an objective, autonomous social actor in service to the public.

\section{Blogs and bloggers from a journalist's perspective}

Journalists also recognize that a shift between news consumer and news producer has occurred. With bloggers exposing the faults and foibles of politicians and journalists alike, blogs, as a medium, have demonstrated the power to create news and become alternative, competing sources of information. For journalists, this elevation of bloggers' prestige may be perceived as getting too close to the boundaries of the journalistic 
profession. Writing for the New York Times editorial pages, a US Seventh Circuit Judge

Richard Posner (2005) stated this threat directly:

Journalists accuse bloggers of having lowered standards. But their real concern is less highminded - it is the threat that bloggers, who are mostly amateurs, pose to professional journalists and their principal employers, the conventional news media. ... The legitimate gripe of the conventional media is not that bloggers undermine the overall accuracy of news reports, but that they are free riders who may, in the long run, undermine the ability of the conventional media to finance the very reporting on which bloggers depend. (pp. 10-11)

At the professional level, then, journalists contend that they are distinct from political bloggers. The title 'journalist' still gives more social power than 'blogger', and that power is rooted in journalism's historical contention that it is a profession which functions at the highest level of political and social institutions. It is considered, in short, the fourth estate of a democracy.

\section{Journalism as a profession}

Research scholars have long wrestled with the fascinating question of whether journalism is a profession, a semi-profession, or perhaps, only an occupation (Dennis and Merrill, 1996). This question is of particular significance to the present study. If journalism is indeed a profession, or at least perceived as one by journalists, how do journalists frame a burgeoning phenomenon in direct opposition to traditional, professionalized norms?

A profession has a unique status in society. The noun declares that members know more than society at large (and their clients, in particular) about the nature of certain spheres of activity. For example, physicians have a better understanding of medicine than their patients, and attorneys are more familiar with the intricacies of law than are their clients. At least two of the demands derived from this basic statement justify what a profession requires of itself and of society: exclusivity and credibility (Hughes, 1971). Professional credibility is also the basis for a profession's insistence on autonomy, including the internal adjudication of its members. A profession thus claims it is the sole possessor of the appropriate tools to take care of its publics. Those recognized as members of a given profession are expected to dedicate all their time and energy to their work, motivated by public rather than private interests (Boode, 1972). Journalists profess they know better than the public how to serve society as reliable distributors of information, opinions and commentaries, playing a watchdog role (Reese, 1990; Schudson, 2003; Weaver and Wilhoit, 1996).

Isolation of a profession from other occupations preserves its special social status and the hierarchical relations between itself, the public and other occupations. Such isolation is accomplished by creating a unique cultural framework (e.g. symbols and professional jargon) and by defining rigid and stringent behavioral norms that obligate members of the profession (as reflected, for example, in a code of ethics). Isolation helps reinforce the profession's authority (and that of its members), rendering it more difficult for citizens and bodies outside it to understand and judge professional decisions while helping 
to increase the profession's prestige in the eyes of the public and other professional groups (Broddason, 1994).

Various studies have indicated that since the 19th century, journalism has developed common norms and work techniques (Schudson, 1978), formulated work patterns for dealing with emergency situations and evaluating changing realities (Tuchman, 1973), and adopted objectivity as its norm (Hallin, 1992; Schiller, 1979; Schudson, 1990). But most journalists are not required to undergo the entrance examinations, formal training, certification and licensing that are common to other professions (Allison, 1986). In fact, a counter-argument is that historically, journalists are - and normatively should be closely tied to the common man in order to perform a free press function within the American democratic system (Fallows, 1996).

American journalism has developed professional characteristics which are historically distinct from its British origins and other European norms, specifically, the profitdriven structure of the American journalism profession and objectivity as a norm. Commercial motives have driven American journalism from its inception, and with the introduction of television, it should not come as a surprise that public-service broadcasting had no strong tradition. The first amendment protected journalists from the government - regarded as the greatest potential threat - but not from the market. Throughout the early 19th century, American journalism also developed an anti-partisan nature or objectivity, distinguishing itself from public relations and political parties (Deuze, 2005; Schudson, 2005).

Schudson (1995) contends that news is a cultural product and, as such, is an outcome of the normative structures of journalism (pp. 1-33). He notes that it is journalism's revered status as a profession that produces a news product that is negative (so it is controversial), detached (so it is objective), technical (so it is standardized) and official (it is dependent on experts and political elites as sources).

The blogosphere has presented journalists with the paradox of covering a communication technology that, at times, overlaps with their own societal function; although some bloggers and users overlook, or out-and-out oppose, journalists' professional standards. Still, from 1999 to 2005, the blogosphere was, first and foremost, an emergent technology which demanded news coverage. When reporting innovation in medicine, technology or science, the press faces one particular conundrum: how to make a new endeavor, procedure, process or finding understandable to a mass audience. While the coverage of bloggers and their actions does not present the same complexities as the coverage of medical or scientific discoveries, it is beneficial to review how journalists as a whole tend to cover technologies that do not overlap with their societal functions.

\section{Press coverage of emergent technology and science}

Technological developments are often heralded as a progressive or revolutionary force within popular publications (books and magazines), civic and governmental organizations, and research communities (Dicken-Garcia, 1998; Kling, 1991; Rosenzweig, 1998). Journalists in particular, however, tend to present an emergent technology in sensational terms (either positively or negatively) while discounting or ignoring specific limitations or methodological concerns expressed inside the scientific community 
(Blume, 1997; Roll-Hansen, 1994). This may be, in part, due to the interdependent relationship between newsrooms and the scientific field, both of whom need each other to spread the word of innovation or, from a more cynical viewpoint, promote their careers and institutions. As Ransohoff and Ransohoff (2001: 185-6) note, though both journalists and scientists are guided by similar professional standards, the combination of the two 'sometimes yields a product that ... conforms to the ideals of neither good science nor good reporting'.

Schwartz et al. (2002) found academic presentations that garnered press coverage from prestigious medical conferences were largely ones with weak designs and small sample sizes. Three years later, one-quarter of them had not been published in academic journals. In another of their studies, Woloshin and Schwartz (2002) found that news releases from prestigious medical journals often over-exaggerated their findings while ignoring the research's limitations or criticism. Blume (1997) found that early news reports on cochlear ear implants promoted the controversial technology as the bionic ear despite the fact that, at the time, the device was still in development and of rather crude quality. Bubela and Caulfield (2004) found news reporting on genetics research fully disclosed the results, but overemphasized the benefits while downplaying the risks of the findings.

The act of making sense of new information and then constructing a message to interpret and convey that information is an issue of schemata and framing. The next section addresses these concepts as they relate to the framing of the blogosphere within press coverage.

\section{Frames, framing and the journalist}

For the purposes of this study, we are addressing framing as the construction of text or media frames and not in the vein of framing effects, which focuses on the influence of frames on audiences' attitudes and behavior (Scheufele, 1999). Frames are related to, but different from, the notion of schemas, which are cognitive organizational processes of the mind. Bartlett (1932) first proposed schemas as a mental tool by which previous knowledge and experiences organize new information and construct themes or models for efficient understanding and memory. Social groups as well as individuals have schemas - societal functions, roles, positions, ethnicity, class, gender - any personal attribute or distinction that defines membership. Self-schemas reflect the group's shared norms, experiences and expectations; and members of one group may hold schemas about another group (Van Dijk, 1988: 100-2).

While schemas are cognitive tools, frames are tools of communication. They are the outcome of strategic communication decisions; namely what information to select and to give salience to when crafting a message (Entman, 1993, 2004). Entman (1993) identified four locations of frames: the communicator, who, consciously or unconsciously, is guided by frames and/or schemas; the text, which may reinforce frames in stock phrases, stereotypes or thematic schemas; the receiver's mind, which may hold personal schemas related to the information, the frame, or the communicator; and culture, where commonly evoked frames become shared schemas. Furthermore, he posits that frames serve four functions: 
to state problems, determine causes, make moral judgements and suggest remedies. A frame may serve one or all of these functions.

While some scholars explain the construction of media frames within a dynamic process between political interests and the media (Bennett, 1996; Bennett et al., 2006; Entmann, 2004; Zaller and Chiu, 1996), others examine journalism's normative structure and community as an explanation (Fishman, 1978; Tuchman, 1973). Since the blogosphere, especially in its early stages, had few experts, we contend the latter conceptualization of news frames is appropriate for this study. When they first confronted blogs and bloggers, journalists had to make sense of the phenomenon themselves before constructing meaning for their audiences. The question becomes, then, did they construct different frames when the context of the blog post overlapped with a journalistic function for society as compared with when it did not?

\section{Research questions}

News media play an important role in framing the public's attitude toward new technologies, especially during their formative years. Given the apparent tension between individual-based blogs and the institutional, financially oriented mainstream news organizations, it is important to ask whether during the blogosphere's formative years, traditional news media presented blogs to the public. News organizations remain the primary source of news for many Americans and, therefore, offer most their first glimpse into the emergent blogosphere. To narrow the focus of this study, the research questions are as follows.

1 Did traditional media frame blogs as a benefit or as a threat, and to whom? Several social actors who might be affected by blogging activity include: political actors, journalists and news media organizations, business and marketing ventures, society at large, as well as individuals and small groups (such as bloggers themselves or communities associated by common concerns).

2 Were blogs framed as a new or a common phenomenon, and how does this frame change over time? Many individuals are reluctant to adopt a new innovation. Typically, they wait for a few 'innovators' to experiment, and only then 'jump on the train' (Rogers, 1995). The framing of a technology as either new or common may affect interested individuals. The question also addresses the introduction of a new medium through the pages of a traditional medium (newspaper), as being an up-and-coming new phenomenon or as a mass occurrence. The variable of time is especially relevant in discovering a tipping point in coverage, when blogging begins to be framed as a common daily activity.

3 Do articles address bloggers as journalists or associate blogging with journalism? From a journalistic perspective, the most potentially threatening role that bloggers may take is a role of a journalist. Still, a number of blog proponents have noted their grassroots nature (Kline and Burstein, 2005; Trippi, 2004), and others perceive blogging as a new form of journalism with the blogger fulfilling a new citizen journalist role (Gillmor, 2004; Rosen, 2004a, 2004b). Can the same type of description be found in newspaper coverage? Using references such as 'citizen journalist', 'new form of journalism' or 'grassroots journalist' for blogs 
or specific bloggers would have passed on some professional benediction from the journalist.

\section{Methods \\ Data collection}

Seven major US newspapers were selected based on their circulation size (all in the US top 15 newspaper markets) and their geographical location across the country. The seven papers were the New York Times (Late East Coast Edition; $N=86$ ), Washington Post $(N=89)$, Los Angeles Times $(N=38)$, Chicago Tribune $(N=50)$, Boston Globe $(N=36)$, San Francisco Chronicle $(N=29)$ and Houston Chronicle $(N=49)$. Using ProQuest search, researchers gathered all newspaper articles (1999-2005) that used the terms blogs, bloggers, blogging, weblogs, web logs or blogosphere in their citations or abstracts. The earlier terminology for blogs as online journals and web journals was also searched and gathered. Duplicate articles (due to syndication) were reduced to one article, and five articles were dropped due to their non-blogging content, leaving a large sample size of articles $(N=377)$.

Because we seek to understand how news media covered a phenomenon that posed a potential external threat, blogs are defined here as free-standing and not associated with the institutional news industry. Journalists' opinion columns on news organizations' websites are sometimes called blogs, but for the purpose of this study, are not considered part of the blogosphere for two core reasons: they are not external to news organizations and, in practice, these blogs are not much different from the opinion columns the news media have always maintained.

\section{Dependent and independent variables}

The first dependent variable (DV) in this study was the value of blogs as framed by the story: a threat or a benefit and to whom. The second DV was the narrative frame of the story: a new or a common phenomenon. The third DV was a frame that associated blogs or bloggers with journalism or journalists. The three independent variables included in the analysis were: a time variable (year of publication), the section of the paper where the article appeared and the newspaper in which the article appeared.

\section{Coding}

A coding instrument was developed from a pilot study that utilized dichotomous coding; every frame variable received a score of ' 1 ' if the frame was present in the story, and of ' 0 ' if it was not. Independent variables such as time (year and month of publication), newspaper and the section of the paper where the story appeared were recorded.

In order to more precisely measure the content of the story - beyond where it appeared in the newspaper - a narrative score was recorded for each story. Decision rules were established for new and common frame variables under this logic: if a story framed blogs as something new, a trend, or an emerging phenomenon, a ' 1 ' was coded for the new frame; if a story framed blogs as an activity that millions of Americans were participating 
in, or if they gave the sense that everyone was blogging, a ' 1 ' was coded for the common frame. If neither appeared in the story, a ' 0 ' was assigned.

The following decision rules determined the dichotomous coding for benefit frames: if a story associated blogs and bloggers with benefits such as personal enjoyment, strengthening bonds within a group with common interests or goals (including bloggers), political reach or influence, financial gains, marketing possibilities, increased communication within a business or organization, branding and marketing opportunities for media organizations (including news organizations), a source of information for journalists, the ability to present hard-to-get information to the public (such as during Hurricane Katrina), or the ability to shed light on salient information ignored or downplayed by the mainstream press; the story received a ' 1 ' for benefit frame.

For the threat frame, if the story associated blogs and bloggers with any loss: job, time, friends, real-world human connections, credibility, criminal activity, limited political influence or reach (due to extreme opinions being given salience or an overall cacophony of voices), or simply due to dull or confusing content; the story received a ' 1 ' for the threat frame.

Pre-analysis of the data highlighted 15 types of actors that either benefited or were threatened by blogs. During data analysis, these subcategories were collapsed due to a small number of observations in categories that were similar in nature. The final list of actor subcategories included: political actors and governmental institutions including the military, federal, state and local governments; journalists/news organizations/journalists who blog (j-bloggers) and consumers of news; individuals and small cohorts including specific bloggers, online and real-world communities; business organizations and marketing endeavors; society at large, including voters; and generalized 'others'.

Finally, each story was coded as to whether it associated blogging with journalism or considered bloggers to be journalists. The decision rule for the blogger as journalist frame was to code the article with a score of ' 1 ' if the blogger was described as any kind of journalist (in his pajamas or otherwise), and if blogging was associated with new journalism, grassroots journalism or a citizens' journalist movement.

Of the corpus 10 percent was randomly drawn to assess intercoder reliability. Due to the dichotomous nature of the coding (for example, zeros were expected for many of the actor categories), two coefficients of overall intercoder reliability are reported in this study: the percentage of agreement and Scott's $\pi$, a conservative statistic that takes into consideration a chance agreement (Krippendorff, 2004). The overall percent agreement was .87 and Scott's $\pi=.72$. Percent agreement and Scott's $\pi$ for the other variables were respectively: blogs as a new phenomenon 1.00 and $\pi=1$; blogs as a common phenomenon .81 and $\pi=.51$; the benefit frame .78 and $\pi=.54$; the threat frame .87 and $\pi=.70$; blogs associated with journalism $.92 ; \pi=.62$.

\section{Findings}

This study aimed to explore how blogs were framed by major newspapers in the USA. Stories associated with blogs or blogging became more frequent from 1999 to 2005 (0, 1, 9, $24,44,86,212$ stories correspondingly). The leading narrative in which blogs are discussed 


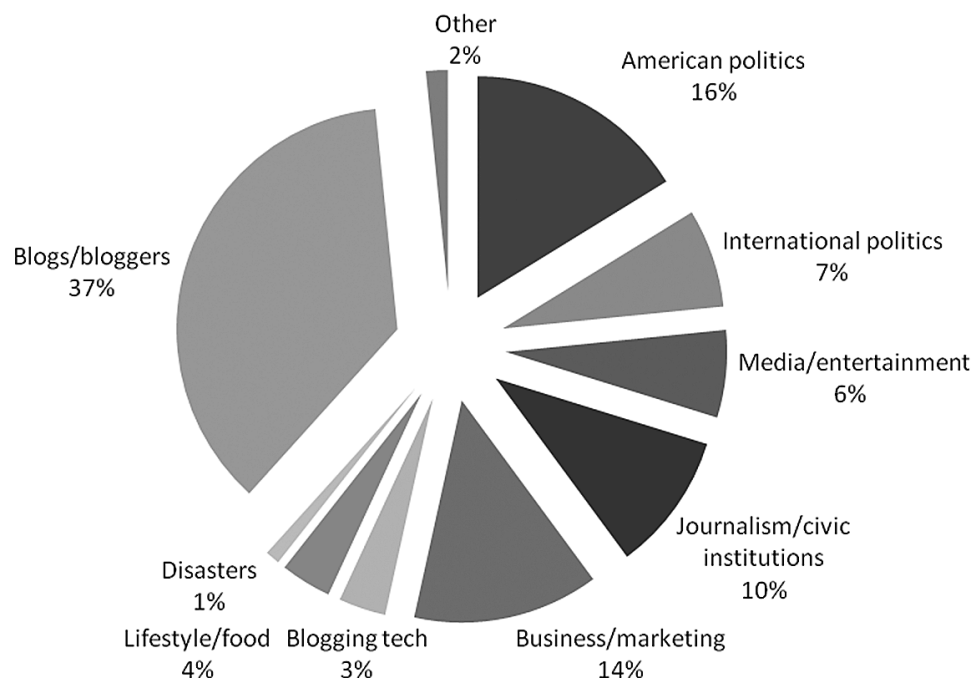

Figure I Distribution of articles by narratives $(N=407)^{*}$

* Many stories had more than one narrative.

is very blog-specific: blogs and bloggers (37\%), which include mainly stories about blogs in general, and about specific blogs or bloggers. Other major narratives were American politics (16.2\%), business (13.6\%), and journalism and media (10.1\%; see Figure 1).

The first research question was: Did traditional media frame blogs as benefit or as a threat, and to whom?

The majority of frames $(n=231)$ describe blogs in terms of their benefits $(61.2 \%)$. When framed as a positive, blogging was most often described as a benefit to individuals and/or small groups, including the bloggers themselves (54.9\%). From there, the beneficiaries of blogging were society at large $(31.1 \%)$, business $(17.7 \%)$, journalism $(17.3 \%)$ and political actors (16.4\%).

About one-third of news frames $(n=136)$ described blogs as a threat $(36 \%)$. Again, within these frames, individuals and small groups were most frequently discussed as being threatened by blogs $(41.9 \%)$, followed by journalists, the news media or their consumers $(33 \%)$, businesses $(14.7 \%)$, political actors $(16.9 \%)$ and, finally, society at large $(10.3 \%)$ (see Table 1$)$.

By and large, framing blogs as a benefit or a threat did not fluctuate much across newspapers. Nevertheless, newspapers that are traditionally considered national papers - the New York Times and the Washington Post-addressed blogs as threats significantly more frequently than local newspapers did (58.1\% compared with $41.9 \%, \chi^{2}=11.65$, $\alpha<0.001)$. The section the article appeared in was not significant.

The second research question was: Were blogs framed as a new or a common phenomenon? How does that change over time? 
Table I Value frames: blogs as benefits or threats and to whom?*

\begin{tabular}{lcclcc}
\hline \multicolumn{2}{l}{ Benefit frames by social groups $(n=23 I)$} & \multicolumn{3}{l}{ Threat frame by social groups $(n=136)$} \\
\hline Political actors & 28 & $(16.5 \%)$ & Political actors & 23 & $(16.9 \%)$ \\
Society & 72 & $(31.2 \%)$ & Society & 14 & $(10.2 \%)$ \\
Business & 41 & $(17.7 \%)$ & Business & 20 & $(14.7 \%)$ \\
Journalism/news orgs & 40 & $(17.3 \%)$ & Journalism/news orgs & 45 & $(33.1 \%)$ \\
Individuals/small groups & 127 & $(55.0 \%)$ & Individuals/small groups & 57 & $(41.9 \%)$ \\
Others & 2 & $(0.9 \%)$ & Others & 7 & $(5.1 \%)$ \\
\hline
\end{tabular}

*Columns may add up to more than the total percentage because some articles addressed more than one benefit or threat.

Table 2 Did the article associate blogging with journalism? By type of newspaper* $(N=376)$

\begin{tabular}{llll}
\hline & No $(n=317)$ & Yes $(n=59)$ & Total \\
\hline National papers & $165(94.3 \%)$ & $10(5.7 \%)$ & 175 \\
Regional/local papers & $152(75.6 \%)$ & $49(24.4 \%)$ & 201
\end{tabular}

$* \chi^{2}=17.40, \alpha<0.001$.

The majority of news frames, across time, associated blogs as a common phenomenon $(67.1 \%)$, whereas blogs were framed as a new phenomenon less than 1 percent of the time $(n=36)$. The difference in percentages of articles that framed blogs as common did not change significantly across time, nor did it show any pattern (Table 2). Not surprisingly, blogs framed as a new phenomenon declined significantly over time, but that number is suspect due to low occurrences. Again, neither newspaper section nor type of newspaper (national or local) was significant in these results.

The third research question was: Do articles address bloggers as journalists or associate blogging with journalism? Overall, the vast majority of articles did not label bloggers as journalists (84.3\%). However, local newspapers associated blogging with journalism more frequently than did the national papers; 49 times compared with only 10, respectively. Explained further, when frames - or articles - associated blogging with journalism, the local newspapers adopted this frame in larger proportions $(24.4 \%)$ than did the national newspapers $(5.7 \%)$. This difference was statistically significant $\left(\chi^{2}=17.40, \alpha<0.001\right)$.

\section{Discussion}

Mainstream media were faced with a dilemma while covering the rise of blogs. Their obligation to provide a well-informed citizenry called for the introduction of blogs to the public. At the same time, the media have a professional duty to protect the uniqueness of their social role as the major information distributors in society. The coverage of blogs tells the story of an attempt to balance these competing interests. 
Blogs were covered first and foremost as a positive but isolated phenomenon. More than one-third of blog-related stories were about blogs and bloggers, with little or no reference to any larger social realm. Furthermore, individuals and small groups were the largest cohort for benefit (more than one-half) and threat frames (about 40\%). In other words, news media portrayed blogs and bloggers mainly as a beneficial phenomenon, but primarily associated them with the individual, private sphere.

Politics and business were less popular frames. About one-fifth of the articles associated blogs with the political sphere and one in seven stories framed blogs with the business world. The portrayal here was less enthusiastic, as news media took a more balanced position, portraying blogs almost equally as both a benefit and threat to politics and businesses.

Only one in ten articles associated blogs and bloggers with journalism or news media. Furthermore, this is the only category where blogs were discussed as a threat more than as a benefit. In other words, blogs were discussed less and mainly as a negative phenomenon only in stories that placed bloggers and journalists in the same field.

From a different perspective, newspapers which traditionally consider themselves national entities (the New York Times and the Washington Post) addressed blogs as threats more frequently when clustered and compared with local newspapers (the Los Angeles Times, the Chicago Tribune, the San Francisco Chronicle and the Boston Globe).

Literature on professionalism indicates that isolation from other occupations preserves its special social status and the hierarchical relations between the profession, the public and other occupations (Broddason, 1994). The coverage of blogs supports these ideas. Blogs were associated with a variety of realms in society, such as individuals, businesses, politics and journalism. However, the closer the realm was to the journalistic world, the less it was discussed in that context - and the more negative the coverage.

The exclusion of blogs from the journalistic domain can be interpreted as a strategy newspapers used to confront the professional tension between traditional journalism and what may be an emerging threat for their profession: blogs. Though it is beyond the scope of this article, it is quite possible that journalists unthinkingly employed this strategy, built-in as it were, to their journalistic toolkit. By framing the blogosphere as a phenomenon that belongs to individuals and the market, traditional media isolated themselves from blogs and bloggers.

In the formative years of the blogosphere, the mainstream media could have constructively addressed the challenges bloggers would face in their efforts to become reliable sources of information. Instead, the media distanced themselves from the blogosphere, and therefore, sent a message of stagnation rather than of innovation. The public, in turn, realized that it should go elsewhere to learn what makes blogs important in society: an additional, narrow in scope and highly opinionated source of information, which can lend effort to an informed citizenry.

News media's framing bloggers as a threat to journalists raises concern about US newspapers' ability to adapt to a changing information world. In a world of media convergence and constant changes in information formats and delivery channels, future studies should examine whether newspapers are taking advantage of or missing opportunities to expose their professional world to the efforts and contributions provided by those without professional credentials. 


\section{Limitations}

The article-gathering procedure via ProQuest poses a limitation. We used blog-related search terms within citations and abstracts of articles. The purpose of this process was to capture articles that addressed the blogosphere directly in order to provide insight into how the mainstream press framed blogging as an emergent, new media phenomenon. However, this decision excluded articles that may have mentioned blogs, but whose main focus was on other events or issues. Another limitation of this study laid in some of the intercoder reliability values. Although the agreement percentages were overall medium to high, values for Scott's $\pi$ test were lower in some categories (common, benefit, journalism). These values, however, should be considered reasonable for the purposes of this study for two reasons. First, Scott's $\pi$ test is considered to be a more conservative or stricter estimation of reliability (Krippendorff, 2004) and the agreement percentages were workable. Second, content analysis was not used for further tests. With the exception of business compared with journalism frames, all comparisons seemed far apart. Finally, this study examines media frames which make a comparison between when the stories' context bumped into the function of journalism and when it did not. As Scheufele (1999) has noted, enquiry into the process of constructing media frames directly is needed, and we argue, especially compelling in an era when the relationship between journalists and the public they serve is undergoing reform. The audience is no longer passive. Research into how mass media institutions and practitioners confront that change is essential. Work of this nature would shed light on the normative and economic structures that bear influence on newsrooms as they adapt to the changing media world populated by grassroots sources such as YouTube, Wikipedia and certain blogs that have, since 2005, staked their reputations on compelling political coverage (such as TalkingPoints Memo, or the Huffington Post). Furthermore, a content analysis cannot answer why national papers reported on blogs differently (more negatively) than local papers did. An examination of news decisions at the level of newsroom behavior (instead of the outcome of that behavior) is needed.

\section{Conclusions}

News organizations have long played a unique role in presenting new technologies to the public (Rogers, 1995). This study shows that journalists reported on blogging in its formative years and framed it as a commonplace occurrence from its naissance. However, unlike many other technological advances, the blogging phenomenon posed a unique dilemma for reporters: how to weigh their obligation to provide the public with a full accounting of the day's news against defending their traditional role of being the information gatekeepers and political agenda setters. Findings from this historical study indicate that newspaper organizations were less open to the notion that this unique form of active and participatory audience benefited journalistic interests. When reporting on blogs or bloggers whose content and work fell within the realm of journalism, journalists framed the phenomenon as a threat twice as much as they framed it as a benefit. This ratio between threat and benefit frames was not found anywhere else in the findings and was, in fact, opposite when examining the dataset as a whole. In other words, overall 
blogs were framed as benefit most of the time, but when it came to the world of journalism then blogs were framed mostly as a threat.

This initial resistance to present the blogosphere as potentially serving an informational function to society is worrying in two ways. These findings suggest that as in other professions, journalists continue to use their power to isolate themselves from those who can potentially threaten their unique social status: in this case, as information providers to democracy (Broddason, 1994). When budgets are cut, subscriptions are down and critics argue that journalists do not fulfill their role of the fourth estate (Bagdikian, 2004; Picard, 1994), as journalists further isolate their profession, they leave the door open for bloggers to step in as a fresh source of news and views (Gillmor, 2004). Subsequently, journalists adopting negative frames when reporting on bloggers' journalistic acts may call into question their credibility and independence as more and more individuals become exposed to blogs via friends and family or due to growing numbers of news stories where bloggers play a pivotal role (such as 'Rathergate').

Well-known bloggers may not be journalists; however, they do perform journalistic acts, such as providing cutting-edge commentary on matters of civil importance or random acts of journalism (Lasica, 2003). To stay relevant, news organizations must approach every technological phenomenon with equal measures of skepticism and awe. Yet the framing of the emergent blogosphere did not seek such a balance. On the blogger side, though, life went on regardless of how they were presented in the news. Then, as it is today, the very society journalists serve is full of individuals who are on their own quest to contribute to society in all ways, including the distribution of the day's news and knowledge. It seems less and less important whether they are in their pajamas or not.

\section{References}

Allison, M. (1986) 'A Literature Review of Approaches to the Professionalism of Journalists', Journal of Mass Media Studies 1(2): 5-19.

Bagdikian, B. (2004) The Media Monopoly. Boston, MA: Beacon Press.

Bartlett, F.C. (1932) Remembering: A Study in Reply to Experimental and Social Psychology. New York: Macmillan.

Bennett, W.L. (1996) 'An Introduction to Journalism Norms and Representations of Politics', Political Communication 13: 373-84.

Bennett, W., R. Lance, G. Lawrence and S. Livingston (2006) 'None Dare Call It Torture: Indexing and the Limits of Press Independence in the Abu Ghraib Scandal', Journal of Communication 56(3): 467-85.

Blood, R. (2000) 'Weblogs: A History and Perspective', URL (consulted December 2008): http:// www.rebeccablood.net/essays/weblog_history.html

Blood, R. (2003) 'Weblogs and Journalism: Do They Connect?', Nieman Reports 57(3): 61-3.

Blume, S.S. (1997) 'The Rhetoric and Counter-rhetoric of a "Bionic" Technology', Science, Technology, and Human Values 22(1): 31-56.

Boode, W. (1972) 'Community within Community: The Professions', in R.M. Pavalko (ed.) Sociological Perspectives on Occupations, pp. 17-25. Itasca, IL: Peacock.

boyd, d. (2004) 'The New Blogocracy', salon.com, 28 July, URL (consulted January 2009): http:// dir.salon.com/story/tech/feature/2004/07/28/demoblog/ 
Broddason, T. (1994) 'The Sacred Side of Professional Journalism,' European Journal of Communication 9: 227-48.

Bubela, T.M. and T.A. Caulfield (2004) 'Do the Print Media "Hype" Genetic Research? A Comparison of Newspaper Stories and Peer-reviewed Research Papers', Canadian Medical Association Journal 170(9): 1399-407.

Burstein, D. (2005) 'Introduction: From Cave Painting to Wonkette: A Short History of Blogging', in D. Kline and D. Burstein (eds) Blog! How the Newest Media Revolution is Changing Politics, Business, and Culture. New York: Squibnocket.

Canfield, K. (2002) 'Web-based "Bloggers” Emerge in Lott Affair', Contra Costa Times, section D, p. 1 (21 December).

Casey, W. (2008) 'Bloggers Plan to Blanket GOP Convention', in National Journal, 31 August, URL (consulted January 2009): http://nationaljournal.com/conventions/co_20080831_6158.php

Democratic National Convention (08DNC) (2008) 'Blogs Credentialed for the Convention', URL (consulted January 2009, but link subsequently removed): www.demconvention.com/ credentialed-blogs

Dennis, E.E. and J.C. Merrill (1996) Media Debates: Issues in Mass Communication. White Plains, NY: Longman.

Deuze, M. (2005) 'What is Journalism?', Journalism 6(4): 442-64.

Dicken-Garcia, H. (1998) 'The Internet and Continuing Historical Discourse', Journalism and Mass Communication Quarterly 75(1): 19-27.

Entman, R.M. (1993) 'Framing: Toward Clarification of a Fractured Paradigm', Journal of Communication 43(4): 51-8.

Entman, R.M. (2004) Projections of Power: Framing News, Public Opinion, and U.S. Foreign Policy. Chicago, IL: University of Chicago Press.

Fallows, J. (1996) Breaking the News: How the Media Undermine the American Democracy. New York: Pantheon Books.

Fishman, M. (1978) 'Crime Waves as Ideology', Social Problems 25(5): 531-43.

Gallagher, D.F. (2002) 'A Rift among Bloggers', New York Times, 10 June, section C; Column 1, Business/Financial Desk, p. 4.

Gillmor, D. (2003) 'Foreword', in S. Bowman, C. Willis and J.D. Lasica (eds) We Media: How Audiences are Shaping the Future of News and Information, p. vi. Reston, VA: Media Center at the American Press Institute, URL (consulted March 2009): http://www.hypergene.net/ wemedia/weblog.php?id=P2

Gillmor, D. (2004) We the Media: Grassroots Journalism by the People for the People. Sebastopol, CA: O’Reilly.

Hafner, K. (2001) 'A Beautiful Life, an Early Death, a Fraud Exposed', 31 May, New York Times, URL (consulted January 2009): http://query.nytimes.com/gst/fullpage.html?res=950CE7DC10 3CF932A05756C0A9679C8B63

Hallin, D. (1992) 'The Passing of "High Modernism” of American Journalism', Journal of Communication 42(3): 14-25.

Herring, S.C., L.A. Scheidt, S. Bonus, and E. Wright (2004) Bridging the Gap: A Genre Analysis of Weblogs. Proceedings of the 37th Hawai'i International Conference on System Sciences (HICSS-37). Los Alamitos: IEEE Computer Society Press, URL (consulted January 2009): http://www.blogninja.com/DDGDD04.doc 
Herring, S.C., L.A. Scheidt, S. Bonus and E. Wright (2005) 'Weblogs as a Bridging Genre', Information, Technology and People 18(2): 142-71.

Herring, S.C., L.A. Scheidt, I. Kouper and E. Wright (2006) 'A Longitudinal Content Analysis of Weblogs: 2003-2004', in M. Tremayne (ed.) Blogging, Citizenship and the Future of Media. London: Routledge, URL (consulted February 2006): http://www.slis.indiana.edu/faculty/ herring/pubs.html

Hughes, E.C. (1971) The Sociological Eye. Chicago, IL: Aldine-Atherton.

Jesdanun, A. (2001) 'Web Authors Turn to Online Logs; Sites Become a Popular Means for Expressing Views after Sept. 11 Attacks', Plain Dealer, Business section, p. 5 (15 October).

Klein, J. (2004) 'I'd Rather Be Blogging', Opinion Journal from the Wall Street Journal editorial page, 13 September, URL (consulted April 2008): http://www.opinionjournal.com/ diary/?id=110005611

Kline, D. and D. Burstein (2005) Blog! How the Newest Media Revolution is Changing Politics, Business, and Culture. New York: Squibnocket.

Kling, R. (1991) 'Computerization and Social Transformations', Science, Technology, and Human Values 16(3): 342-67.

Krippendorff, K. (2004) 'Reliability in Content Analysis - Some Common Misconceptions and Recommendations', Human Communication Research 30(3): 411-33.

Lasica, J.D. (2003) 'Blogs and Journalism Need Each Other', Neiman Reports 57(3): 70-4.

Norris, M. (2006) 'The Journalistic Response to Hurricane Katrina', Minneapolis Public Radio, URL (consulted September 2009): http://minnesota.publicradio.org/display/web/2006/04/24/midday2/

Picard, R.G. (1994) The Press and the Decline of Democracy: The Democratic Socialist Response in Public Policy. Westport, CT: Greenwood.

Posner, R.A. (2005) 'Bad News', 31 July, New York Times, section 7, p. 1.

Preiss, C. (2004) 'Blogger Takes on Big Media from Apple Valley Home', Star-Tribune, Metro Edition, p. 1 (6 October).

Quandt, T. (2005) 'Research into Media Convergence-Toward a Multidisciplinary, Multiperspective Approach', paper presented at the 55th International Communication Association conference, New York, NY, 26-30 May.

Ransohoff, D.F. and R.M. Ransohoff (2001) 'Sensationalism in the Media: When Scientists and Journalists May Be Complicit Collaborators', Effective Clinical Practice 4(4): 185-8.

Reese, S. (1990) 'The News Paradigm and the Ideology of Objectivity: A Socialist at the Wall Street Journal', Critical Studies in Mass Communication 7(4): 390-409.

Rogers, E.M. (1995) Diffusion of Innovations. New York: Free Press.

Roll-Hansen, N. (1994) 'Science, Politics, and the Mass Media: On Biased Communication of Environmental Issues', Science, Technology, and Human Values 19(3): 324-41.

Rosen, J. (2004a) 'Top Ten Ideas of '04: News Turns from a Lecture to a Conversation', URL (consulted October 2007): http://journalism.nyu.edu/pubzone/weblogs/pressthink/2004/12/29/ tp04_lctr.html

Rosen, J. (2004b) 'Top Ten Ideas of '04: Open Source Journalism, or “My Readers Know More Than I Do"”, URL (consulted October 2007): http://journalism.nyu.edu/pubzone/weblogs/ pressthink/2004/12/28/tptn04_opsc.html

Rosenzweig, R. (1998) 'Wizards, Bureaucrats, Warriors and Hackers: Writing the History of the Internet', American Historical Review 103(5): 1530-52. 
Scheufele, D.A. (1999) 'Framing as a Theory of Media Effects', Journal of Communication 49(1): 103-22.

Schiller, D. (1979) 'An Historical Approach to Objectivity and Professionalism in American News Reporting,' Journal of Communication 29(4): 46-57.

Schorow, S. (2001) 'People Turn to Internet to Learn News, Express Views', 18 September, Boston Herald, Arts and Lifestyle, p. 49.

Schudson, M. (1978) Discovering the News. New York: Basic Books.

Schudson, M. (1990) Origins of the Ideal of Objectivity in the Professions. New York: Garland.

Schudson, M. (1995) The Power of News. Cambridge, MA: Harvard University Press.

Schudson, M. (2003) Sociology of News. New York: W.W. Norton.

Schudson, M. (2005) 'The US Model of Journalism: Exception or Exemplar?', in H. de Burgh (ed.) Making Journalists, pp. 94-106. London: Routledge.

Schwartz, L.M., S. Woloshin and L. Baczek (2002) 'Media Coverage of Scientific Meetings: Too Much, Too Soon?', Journal of American Medical Association 287(21): 2859-63.

Smith, A. (2008) 'New Numbers for Blogging and Blog Readership', Pew Internet and American Life Project, 22 July, URL (consulted April 2008): http://www.pewinternet.org/PPF/p/1494/ pipcomments.asp

Surowiecki, J. (2004) The Wisdom of Crowds: Why the Many are Smarter than the Few and How Collective Wisdom Shapes Business, Economies, Societies, and Nations. New York: Doubleday.

Thomas, E. (2006) 'A Secret Life; Mark Foley's Explicit E-mails Could Bring Down the GOP. His Story, and the Fallout', 16 October, Newsweek, US Edition, p. 28.

Trippi, J. (2004) The Revolution will not be Televised: Democracy, the Internet, and the Overthrow of Everything. New York: Harper Collins.

Tuchman, G. (1973) 'Making News by Doing Work: Routinizing the Unexpected', American Journal of Sociology 79(1): 111-31.

Van Dijk, T.A. (1988) News as Discourse. Hillsdale, NJ: L. Erlbaum Associates.

Weaver, D.H. and G.C. Wilhoit (1996) The American Journalist in the 1990s: US News People at the End of an Era. Mahwah, NJ: Erlbaum.

Winer, D. (2002) 'The History of Weblogs', URL (consulted December 2007): http://oldweblogscomblog.scripting.com/historyOfWeblogs

Woloshin, S. and L.M. Schwartz (2002) 'Press Releases: Translating Research into News', Journal of American Medical Association 287(21): 2856-8.

Zaller, J. and D. Chiu (1996) 'Government's Little Helper: U.S. Press Coverage of Foreign Policy Crises', 1945-1991', Political Communication 13(4): 385.

Julie Jones is Associate Professor at the Gaylord College of Journalism and Mass Communication at the University of Oklahoma. Her research centers on the intersection between social media and mass media, specifically with legacy journalism.

Itai Himelboim is Assistant Professor in the Telecommunications Department, Grady College of Journalism and Mass Communication, University of Georgia. In his research, he examines computer-mediated social networks in the context of political and international communications. Address: Grady College of Journal and Mass Communication, Journalism Building, 120 Hooper St, Athens, GA 30602-3018, USA. [email: itai@uga.edu] 